\title{
Assessment of Paediatric usage of Antibiotics in Moradabad Region
}

\author{
Shiv K Agarwal ${ }^{1}$ and Jagdish K Sahu*2 \\ ${ }^{1}$ Pharmacy Academy, IFTM University, Moradabad, India \\ ${ }^{2}$ Kharvel Subharti College of Pharmacy, Swami Vivekanand Subharti University, Meerut, India
}

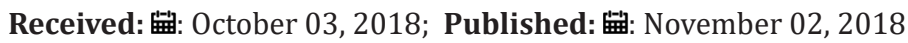

*Corresponding author: Jagdish K Sahu, Kharvel Subharti College of Pharmacy, Swami Vivekanand Subharti University, Meerut, India

\begin{abstract}
The objective of this study was to assess the use of antibiotics in paediatric patients and to analyze rationality \& irrationality of prescriptions. This observational and prospective study was was carried out for 3 months duration between January to March, 2018 in two hospitals of Moradabad (U.P.) India. Out of 521 prescriptions which are selected randomly, 230 prescriptions received antibiotics. Maximum Antibiotic prescriptions were found in the age group of 1-6 years. Cephalosporins were the most commonly prescribed antibiotic group. Cephalexin was the leading antibiotic prescribed followed by Cefpodoxime. The antibiotic prescription should be made compliant with guidelines of World Health Organization (WHO) and rational plans should be executed to control antibiotic use mainly focus on patient population especially in children and infants.
\end{abstract}

\section{Introduction}

Resistance to antibiotic drugs is increasing across the world and reported cases among them are highest in India [1,2]. A recent report stated that resistance to last-resort antibiotics amplified between 2008 and 2014 [3]. Antibiotics are the main agents for treatment of infections and are among the most commonly recommended drugs in Paediatrics department. Worldwide population constitute of about $28 \%$ of children and infants who are most susceptible to diseases due to under development of immune system. More than a few studies reported that $55 \%$ to $90 \%$ of children receive antibiotics in developed and developing countries prescribed by doctors [4-6].

Burden of selection of antibiotic drug is a primary driver of development of resistance [7], and there is an urgent need to reduce misuse and overuse of antibiotics. Assessment of antibiotic use in hospitals can provide an insight into various patterns of antibiotic use, may help highlight differences in prescribing practices among hospitals, and can identify opportunities for improvement. Evidences and data on antibiotic usage from survey could be used to design, implement, and assess the effects of antimicrobial policies [8]. In this study, we examined the prevalence of and indications of antibiotic use, as well as the antibiotic drugs used among hospitalized children, by conducting assessment and survey in two hospitals of Moradabad (Uttar Pradesh), India [9].

\section{Materials and Methods}

The survey was conducted by randomly collecting 521 prescriptions of paediatric patients during February 2018 to April 2018. Among them, the prescriptions where antibiotics have prescribed for various diseases, were separated out. The prescriptions containing antibiotics were divided into patient's age having less than 1 year and 1-6 yrs. The prescriptions were then evaluated according to most commonly used antibiotics.

Table 1: Antibiotics prescribed with respect to patient's age.

\begin{tabular}{|c|c|c|c|}
\hline S. No. & Age Group & $\begin{array}{l}\text { No. of Prescriptions } \\
(\%)(\mathrm{N}=230)\end{array}$ & $\begin{array}{c}\text { Antibiotics Prescribed } \\
\text { (\%) }\end{array}$ \\
\hline \multirow{4}{*}{1.} & \multirow{4}{*}{$<1$ year } & \multirow{4}{*}{$111(48.26 \%)$} & Cephalexin (71.04 \%) \\
\hline & & & Cefpodoxine (28.86 \%) \\
\hline & & & Amoxicillin (22.2\%) \\
\hline & & & Norfloxacin (1.11\%) \\
\hline \multirow{5}{*}{2.} & \multirow{5}{*}{$1-6$ years } & \multirow{5}{*}{119 (51.73 \%) } & Cefpodoxine (41.65 \%) \\
\hline & & & Amoxicillin (35.7 \%) \\
\hline & & & Norfloxacin (29.75 \%) \\
\hline & & & Cephalexin (17.85 \%) \\
\hline & & & Azithromycin (16.66\%) \\
\hline
\end{tabular}




\section{Results and Discussion}

The survey analysis showed that among the total number of antibiotics prescribed prescriptions ( $\mathrm{n}=230), 48 \%$ were infants and $52 \%$ belong to the age group of 1-6 yrs. The most common category of antibiotics that was prescribed by maximum paediatric specialists was cephalosporins in which cephalexin (34.34\%) was the major drug to be used. Beta-lactam antibiotic was the next category of antibiotics that was prescribed among which Cefpodoxime (26.52) was the most commonly used drug (Table 1). The above survey analysis has been represented in Table 2 .

Table 2: Most common antibiotics used.

\begin{tabular}{|c|c|c|c|}
\hline S. No. & Category & Most Commonly Used Drug & \% Of Prescribed Prescriptions (N=230) \\
\hline 1. & Cephalosporins & Cephalexin & 34.34 \\
\hline 2. & Beta-lactam antibiotic & Cefpodoxime & 26.52 \\
\hline 3. & Penicillin & Amoxicillin & 21.73 \\
\hline 4. & Quinolones & Norfloxacin & 11.3 \\
\hline 5. & Macrolides & Azithromycin & 6.08 \\
\hline
\end{tabular}

\section{Conclusion}

The present survey concluded that the most common antibiotic prescribed in paediatric patients belong to the class of cephalosporins among which cephalexin was most frequently used drug. Beta-lactam antibiotic was the next category of antibiotics that was prescribed among which cefpodoxime was very common.

\section{References}

1. Laxminarayan R, Matsoso P Pant S, Brower C, Rottingen JA (2016) Access to effective antimicrobials: A worldwide challenge. Lancet 387(10014): 168-175.

2. Laxminarayan R, Duse A, Wattal C, Zaidi AK, Wertheim HF, et al. (2013) Antibiotic resistance: The need for global solutions. Lancet Infect Dis 13(12): 1057-1098.

3. Gandra S, Mojica N, Klein EY, Ashok A, Nerurkar V, et al. (2016) Trends in antibiotic resistance among major bacterial pathogens isolated from blood cultures tested at a large private laboratory network in India 2008-2014. Int J Infect Dis 50: 75-82.

ISSN: 2574-1241

DOI: $10.26717 / B J S T R .2018 .10 .002000$

Jagdish K Sahu. Biomed J Sci \& Tech Res

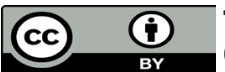

This work is licensed under Creative Commons Attribution 4.0 License

Submission Link: https://biomedres.us/submit-manuscript.php
4. Moorthi C, Paul PR, Srinivasan A, Senthil CK (2011) Irrational use of antibiotics in paediatric prescriptions: A pilot study at community pharmacy in Erode City. Der Pharmacia Letter 3(3): 171-177.

5. Paluck E, Katzentein D, Frankish CJ, Herbert CP, Milner R (2001) Prescribing practices and attitudes toward giving children antibiotics. Can Fam Physician 47: 521-527.

6. Pennie RA (1998) Prospective study of antibiotic prescribing for children. Can Fam Physician 44: 1850-1856.

7. World Health Organization (WHO). WHO's First Global Report on Antibiotic Resistance Reveals Serious, Worldwide Threat to Public Health.

8. Skoog G, Struwe J, Cars O, Hanberger H, Odenholt I, et al. (2016) Repeated nationwide point-prevalence surveys of antimicrobial use in Swedish hospitals: Data for actions 2003-2010. Euro Surveill 21(25).

9. Samreen J, Sahu JK (2017) A Market Survey of Amlodipine (Antihypertensive) in Moradabad City. Curr Res Pharm Sci 07 (01): 3032.

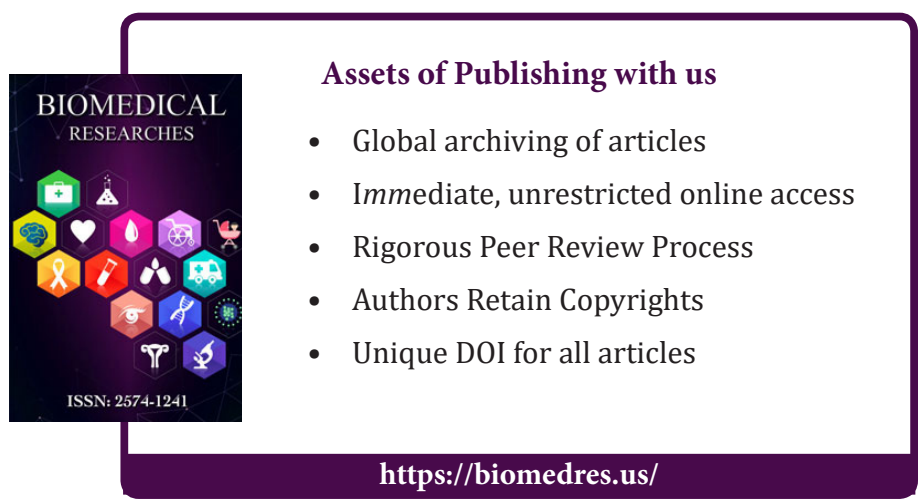

